\title{
The Risk of Developing Coal Workers' Pneumoconiosis in a German Inception Cohort of Coal Miners of Ruhr Area - Re- sults after 30 Years of Follow-up
}

\author{
M Yong ${ }^{1 *}$, L Anderle ${ }^{1}, H$ Lenaerts ${ }^{2}$, R Derwall ${ }^{2}$, D Brand ${ }^{2}$ and P Morfeld ${ }^{1,3}$ \\ ${ }^{1}$ Institute for Occupational Epidemiology and Risk Assessment, Evonik Industries AG, Germany \\ ${ }^{2}$ Department of Occupational Medicine, RAG AG, Germany \\ ${ }^{3}$ Institute of Policlinic for Occupational Medicine, Environmental Medicine and Preventive Research, University \\ of Cologne, Cologne, Germany
}

\begin{abstract}
Comprehensive dust control and health protection measures have been implemented to prevent coal workers' pneumoconiosis (CWP) in German collieries since several decades. The present study evaluates the risk of developing CWP related to exposure to respirable coal mine dust containing quartz.

A complete inception cohort of 1369 coal miners who started working underground between 1974 and 1979 in the Ruhr area has been provided a continuous health surveillance program, including radiographic chest examination. From the continuous exposure monitoring, exposure duration, long-term average, and cumulative concentration of dusts were derived to be exposure metrics. To estimate the risk of developing CWP, Cox proportional hazard models were used, in which the exposure was treated in a time-dependent manner. A cumulative incidence rate of 2.34 per 1000 person-years for CWP $0 / 1$ (71 cases) or 1/0 ( 1 case), no CWP $\geq 1 / 1$ was found. The implemented health protect measures seem to be effective for disease prevention.
\end{abstract}

Keywords

Coal mine, Crystalline silica, Coal workers' pneumoconiosis, Retrospective cohort

\section{Introduction}

The effects of dust exposure on human health are once again the focus of research since European regulation evaluates the carcinogenicity of granular biopersistent substances without specific toxicity (GBS). Particles, such as carbon black, titanium dioxide, and coal mine dusts have the chemical and physical property of GBS. Coal mining is amongst the most intensively investigated occupational group, for the reason that exposure to coal mine dust has usually a larger scale than that of other dusts. Therefore, studies of coal miners provide the best evidence for epidemiological findings concerning non-malignant respiratory diseases and lung cancer risk. Accordingly, dust-related health outcomes have been studied, such as detrimental effects on lung function and development of chronic obstructive pulmonary diseases [1-3]. Large cohort studies from US, UK, and Germany studied extensively the risk of lung cancer [4-6].
In Germany, strenuous endeavor has been made to control for dust exposure and monitor health of the miners for decades. The limit value of 8-h time weighted average (TWA) has been declined stepwise from $10 \mathrm{mg} / \mathrm{m}^{3}$ in 1974 to $8.1 \mathrm{mg} / \mathrm{m}^{3}$ from 1976 to 1980 , and further declined to $6.4 \mathrm{mg} / \mathrm{m}^{3}$ in the 80 's. With the Regulation of Health Protection in Mining of July 31, 1991 [7], the work place limit

\begin{abstract}
*Corresponding author: Dr. Mei Yong, PD, Institute for Occupational Epidemiology and Risk Assessment of Evonik Industries, Rellinghauser Straße 1-11, 45128 Essen, Germany, Tel: +49-201-177-4400, Fax: +49-201-177-4403, E-mail: mei.yong@evonik.com
\end{abstract}

Received: February 08, 2018; Accepted: April 12, 2018; Published online: April 14, 2018

Citation: Yong M, Anderle L, Lenaerts $\mathrm{H}$, et al. (2018) The Risk of Developing Coal Workers' Pneumoconiosis in a German Inception Cohort of Coal Miners of Ruhr Area - Results after 30 Years of Follow-up. Ann Lung Cancer 2(1):39-47

Copyright: (c) 2018 Yong M, et al. This is an open-access article distributed under the terms of the Creative Commons Attribution License, which permits unrestricted use, distribution, and reproduction in any medium, provided the original author and source are credited. 
Citation: Yong M, Anderle L, Lenaerts H, et al. (2018) The Risk of Developing Coal Workers' Pneumoconiosis in a German Inception Cohort of Coal Miners of Ruhr Area - Results after 30 Years of Follow-up. Ann Lung Cancer 2(1):39-47

value for respirable dust was set that an 8-h TWA of $4.0 \mathrm{mg} /$ $\mathrm{m}^{3}$ for respirable dust and $0.2 \mathrm{mg} / \mathrm{m}^{3}$ for quartz component (> 5\% mass) should not be exceeded. The limit value was determined based on 220 shifts per year during a time period of two years. In 2012, the German MAK Commission (Commission for Investigation of Health Hazards of Chemical Compounds in the Work Area) defined the new 8-h TWA for GBS at $0.3 \mathrm{mg} / \mathrm{m}^{3}$ multiply a density in $1 \mathrm{~g} / \mathrm{cm}^{3}$ [8]. The MAK Commission used a translational approach of rat overload experiments into human equivalent concentrations (HECs) to derive an occupational exposure limit, without considering the human evidence from the epidemiological studies. This MAK approach has been critically examined in terms of reliability of translational models [9].

Against this background, we assess the risk of developing pneumoconiosis in association with respirable coal mine dust and quartz in an inception cohort study, and will address the extent to which limits will require reduction, and regulatory changes connecting to working durations in particular.

\section{Material and Methods}

\section{Study setting and study population}

This study was designed as a retrospective cohort study of coal miners working underground. It is a part of an extensive epidemiological study program, which was described more in detail in previous reports [10,11]. In 1974, the gravimetric dust measurements were introduced in the Ruhr coalmine area, so that the respirable non-quartz dust fraction and respirable quartz fraction can be identified. The present report is based on an inception cohort that restricts to all newly hired coal miners between 1974 and 1979 with no prior relevant exposure.

This inception cohort comprises 1369 coal miners of
Ruhr Coal Mine AG (RAG) who started work underground at two big collieries (670 in Heinrich Robert and 699 in Walsum) in the Ruhr area. At Heinrich Robert colliery, high rank coking coal was mined which is used in steel production, while at Walsum colliery low rank gas and flaming coal was mined, which is used in energy production. Hence, this study population represents the typical stratigraphic horizons of coal mines in the Ruhr area. The characteristics of the study population are summarized in Table 1.

\section{Medical program overview}

Back to the 50's, preventive medical examinations have been provided to miners working in underground according to the European Coal and Steel Community. In the 60's, the Amendment of Mining Ordinance came in force in which a program for occupational medical examination was recommended for miners [12]. The mining regulation of the North Rhine-Westphalia Mining Inspectorate $[13,14]$ and the Regulation on Health Protection in Mining [7] specified occupational health examinations for coal miners. Regulations required a minimal medical examination program and document in relation to identified health hazards, i.e. either past or present dust exposure, within the workplace. Within RAG, the largest German coal mining company, a comprehensive health protection program is subject to corporate health protection and disease prevention commitments. All miners working underground must undergo a qualification examination at entry to exclude potential risk. During the occupational mining career, a continuous health surveillance program, including physical examination, lung function tests and chest posterior- anterior radiographs every two years, was provided to identify impairment of lung function and prevent developing coal workers' pneumoconiosis.

Table 1: Characteristics of inception cohort of 1369 coal miners.

\begin{tabular}{|c|c|c|c|c|c|c|}
\hline & N (\%) & mean & sd & median & $\min$ & $\max$ \\
\hline Age at entry to FU (yrs) & 1369 & 19.3 & 4.4 & 18 & 16 & 48 \\
\hline Age at end of FU (yrs) & 1369 & 40.7 & 8.6 & 44 & 20 & 60 \\
\hline Duration of FU (yrs) & 1369 & 21.4 & 8.2 & 25 & 3 & 32 \\
\hline BMI at entry & 1369 & 22.6 & 3.1 & 22 & 16.3 & 43.6 \\
\hline $\mathrm{BMI}$ at end of FU & 1369 & 27.2 & 4.6 & 28.8 & 16.4 & 67.8 \\
\hline Smoking status at entry of FU & & Pack-years & & & & \\
\hline Current smoker, $\mathrm{N}(\%)$ & $365(27)$ & 3 & 3.2 & 2 & 0.1 & 28 \\
\hline Former smoker, $\mathrm{N}(\%)$ & $5(0.4)$ & 5.1 & 5 & 3.75 & 0.5 & 13.5 \\
\hline Never smoker, $\mathrm{N}(\%)$ & $999(73)$ & 0 & 0 & 0 & 0 & 0 \\
\hline Smoking status at end of FU & & Pack-years & & & & \\
\hline Current smoker, N (\%) & $394(29)$ & 17.4 & 9.9 & 16 & 0.6 & 54.4 \\
\hline Former smoker, $\mathrm{N}(\%)$ & $603(44)$ & 12.9 & 9.8 & 11.1 & 0.1 & 84 \\
\hline Never smoker, $\mathrm{N}(\%)$ & $372(27)$ & 0 & 0 & 0 & 0 & 0 \\
\hline \multicolumn{7}{|l|}{ Nationality } \\
\hline German, N (\%) & $1168(85)$ & & & & & \\
\hline Other, N (\%) & $201(15)$ & & & & & \\
\hline
\end{tabular}

FU: Follow-up; sd: Standard deviation; min: Minimum; max: Maximum. 
Citation: Yong M, Anderle L, Lenaerts H, et al. (2018) The Risk of Developing Coal Workers' Pneumoconiosis in a German Inception Cohort of Coal Miners of Ruhr Area - Results after 30 Years of Follow-up. Ann Lung Cancer 2(1):39-47

\section{Medical data}

A total of 16,205 chest radiographs were performed for the study population of 1369 miners during the follow-up period from 1974 to 2004, which corresponds well to an average examination interval of 2 years for each. In each medical department of the sites, two experienced occupational physicians formed a team to read the radiographs independently for the presence, profusion, and type of lung parenchymal abnormalities according to the International Labor Organization's International Classification of Radiographs of Pneumoconiosis [15], supplemented by the complementary German subcategory films for CWP reading [16]. The profusion (concentration) of small opacities is classified on a 4-point major category scale $(0,1,2$ or 3$)$; category 0 refers to the absence of small opacity. Each major category is divided into three, giving 12 ordered subcategories of increasing profusion: $0 /-, 0 / 0,0 / 1,1 / 0,1 / 1,1 / 2,2 / 1,2 / 2,2 / 3,3 / 2$, $3 / 3$, and $3 /+$. Categories $0 / 1$ and $1 / 0$ refer to "suspect" pneumoconiosis [15], while the categories $\geq 1 / 1$ are the manifest CWP cases. Based on a list of cohort members which was assorted from the Institute of Occupational Science of RAG, the radiographs accompanying with a documentation sheet were prepared for evaluation. After each reading by one physician of the team, another documentation sheet accompanying with the radiograph were prepared for the second reading, blinded from the results of the first reading. Until 2004, all radiographs were read on a lightbox, independently by at least two experienced occupational health physicians. The results of the double readings were then compared within the Institute of Occupational Science of RAG. In case of discrepancy of more than one category (for example 0/1 and $1 / 0$ ), a third reading was required and a consensus was achieved.

The basic anthropometric data of body weight and height, as well as smoking habits were traced and collected for the study participants. Based on their reported smoking status during each medical examination, the employees are classified into active smokers, former smokers, and never smokers. Pack-years were calculated based on self-reporting. For handling the missing information, "last observation carried forward" approach was used.

\section{Dust monitoring program}

At RAG, the dust measurements were carried out gravimetrically with the MPG II [17] reference-measuring device that was launched in 1974. This made it possible to measure a precisely defined dust fraction and the components of the respirable coal mine dust sample (respirable quartz and respirable non-quartz dust) could be quantified. Respirable dust that can be retained in the alveoli is defined according to Johannesburg Convention and EN 481 [18]. Gravimetric dust samples were analyzed by infrared spectroscopy to determine the quartz dust fraction.

Briefly, with the launch of gravimetric dust measurement in the Ruhr coal mining area, limit values for dust exposure were defined with respect to respirable coal mine dust and quartz dust at the underground workplaces. To classify a workplace by the concentration of respirable dust although it contains quartz, the quartz content in the dust sample had to be below 5\%. Otherwise, it had to be classified by the respirable quartz concentration.

Quartz dust determination is based on infrared spectroscopy of gravimetric respirable dust samples. To be analyzed reliably the coal mine dust samples must be large enough, i.e. the mass of the sample has to be large enough. Whereas, situations exist underground where sampling found no quartz in the respirable dust although the infrared spectroscopy could be performed reliably. Thus, it is not necessarily that all coalmine dust samples entail quartz dust.

The dust exposure of the coal miners in the study was quantified according to an individual performance record since January 1, 1974. This performance record was adjusted multiple times during the study period, but contained throughout information about medical examinations, duration and type of employment, respirable dust concentrations in the operation, and person-related dust exposure values. The last version was developed according to the Regulation on Health Protection in Mining $[7,19]$. These data were then used in the shift schedule system at RAG to control for the long-term exposure limit value defined by the authorities. Bauer [19] describes this performance record system in further details.

Based on the documentation system at RAG, in which the shift data and performance records were entered, the type, scope and place of job activity, 8-h shift average dust concentration for each underground employee was available for the study period from 1974 to 2004 .

Regular dust monitoring and work force deployment based on individual exposure situation and health status can be traced back to 1957 from the regional mining authority [19]. Afterwards, regulatory measures have been implemented across the collieries according to the mining regulation of the North Rhine-Westphalia Mining Inspectorate, which have been improved during the time $[13,14]$. In RAG, a dose-based concept for dust control, based on the cumulative exposure, has been implemented throughout their collieries since 1974. This concept foresees that miners with exposure to respirable dusts must not exceed a limit value for cumulative exposure to respirable dust evaluated for each miner over an assess- 
Citation: Yong M, Anderle L, Lenaerts H, et al. (2018) The Risk of Developing Coal Workers' Pneumoconiosis in a German Inception Cohort of Coal Miners of Ruhr Area - Results after 30 Years of Follow-up. Ann Lung Cancer 2(1):39-47

ment period of 2 years. Four categories of dust exposure in terms of 8-h average concentration were defined [19]. All person-related exposure was entered in a computer-assisted system. In case of exceeding the expected exposure, the miner must be deployed to other work places with lower concentration.

This concept requires an on-going dust monitoring and a timely steering of deployment. A sufficient personnel reservoir and additional organizational effort are necessary for a successful implementation in practice.

\section{Exposure assessment}

The present study focuses on two components, respirable quartz dust and respirable coal mine dust. The continuing dust monitoring makes it possible that all exposure metrics for each individual can be extracted or derived according to time. The following exposure metrics are used for risk estimation, in a time-dependent manner:

- Exposure duration: The number of underground shifts exposed to respirable coal mine dust and quartz are translated into dust-years and quartz-years, respectively.

- Annual cumulative exposure: Is a cumulative integral of shift-average concentration and number of shifts performed in a given year.

- Total cumulative exposure: Is a cumulative integral of shift-average concentration and number of shifts performed for a given exposure period.

- Long-term average concentration: Is the cumulative exposure up to a given time divided by the corresponding exposure duration for the given exposure period.

\section{Statistical analyses}

With respect to the incident risk of CWP categories $\geq 0 / 1$, time-dependent Cox proportional hazards regression models ("Cox analyses"), with age as the time variable [20], were fitted [21,22]. The date of the last available X-ray examination was used as end of follow-up in non-cases. To be noted, one person had a preliminary stage of $0 / 1$ prior to developing a CWP $=1 / 0$. For Cox regression analysis, time to first event, i.e. $\mathrm{CWP}=0 / 1$ was considered for this person. To estimate the effect of exposure to respirable coal mine dust or respirable quartz, two approaches were used: (i) Cumulative dust exposure; (ii) Long-term average dust exposure in combination with exposure duration was considered in the models, respectively in linear or logarithmic form. To set-up these analyses the individual time-dependent exposure data sets for the respirable coal mine dust and quartz were merged with the data set including fixed individual information on height, weight, nationality, smoking status, coal type, and censoring information. In Cox analyses, we applied a binary indicator to represent nationality (German: Yes or No). In respect to smoking status, the miners were categorized into active smokers and former smokers, taking never smokers as reference. We performed the time-dependent set-up across attained age as the basic time variable with staggered entry using the survival time set-up (stset) features of Stata.

All calculations were done with the Stata Version 13 [23] statistics package. A value of $5 \%$ was applied throughout as statistical significance level.

\section{Results}

Descriptive characteristics of the inception cohort of 1369 coal miners are given in Table 1. Follow-up started on average at the age of 19.3 years, with $9(0.7 \%)$ exceptions aged between 40 and 50 years. The duration of employment was on average 22.4 years, ranged from 4 to 33 years. At entry, body mass index (BMI) was on average 22.6, ranged from 16.3 to 43.6 . Almost $27 \%$ and $73 \%$ of the miners have reported respectively to be active and never smokers at entry of follow-up, while at the end of the study $29 \%, 44 \%$, and $27 \%$ of the miners reported to be active, former and never smokers, respectively. Most of the study participants are German.

\section{Exposure metrics}

Table 2 summarizes the distributions of personal exposure metrics of respirable coal mine dust and respirable quartz. The average duration of exposure to respirable dust and quartz was 15.0 dust-years (range:

Table 2: Distribution of exposure metrics for respirable coal mine dust and quartz in this inception cohort of 1369 coal miners.

\begin{tabular}{|l|l|l|l|l|l|l|l|}
\hline & mean & sd & $\mathbf{1 . Q}$ & median & $\mathbf{3 . Q}$ & min & max \\
\hline Respirable coal mine dust & & & & & & \\
\hline long-term average concentration $\left(\mathrm{mg} / \mathrm{m}^{3}\right)$ & 2.48 & 0.65 & 2.01 & 2.34 & 2.88 & 0.84 & 5.04 \\
\hline duration of exposure (dust-years) & 14.97 & 6.78 & 10.08 & 16.89 & 20.38 & 0.51 & 28 \\
\hline cum. exposure $\left(\mathrm{mg} / \mathrm{m}^{3}\right.$-years) & 37.06 & 19.8 & 23.37 & 36.87 & 48.5 & 1.13 & 100.15 \\
\hline Respirable quartz & & & & & & & \\
\hline long-term average concentration $\left(\mathrm{mg} / \mathrm{m}^{3}\right)$ & 0.09 & 0.03 & 0.06 & 0.09 & 0.11 & 0 & 0.26 \\
\hline duration of exposure (quartz-years) & 11.32 & 5.89 & 6.38 & 12.81 & 15.9 & 0 & 22.86 \\
\hline cum. exposure $\left(\mathrm{mg} / \mathrm{m}^{3}\right.$-years) & 1.04 & 0.67 & 0.48 & 0.98 & 1.52 & 0 & 3.76 \\
\hline
\end{tabular}

sd: Standard deviation; 1.Q: Lower quartile; 3.Q: Upper quartile; min: Minimum; max: Maximum. 
Citation: Yong M, Anderle L, Lenaerts H, et al. (2018) The Risk of Developing Coal Workers' Pneumoconiosis in a German Inception Cohort of Coal Miners of Ruhr Area - Results after 30 Years of Follow-up. Ann Lung Cancer 2(1):39-47

Table 3: Cox regression models: Hazard ratios for CWP $\geq 0 / 1$ and cumulative exposure to respirable coal mine dust, or mean concentration and exposure duration, and covariables. No. of subjects $=1369$, No. of cases $=72$.

\begin{tabular}{|c|c|c|c|c|c|}
\hline \multirow{2}{*}{\begin{tabular}{|l|} 
Covariable \\
Approach 1 \\
\end{tabular}} & \multirow[t]{2}{*}{ Haz. ratio } & \multirow[t]{2}{*}{ Std. err } & \multicolumn{2}{|c|}{$95 \% \mathrm{CI}$} & \multirow[t]{2}{*}{$P>|z|$} \\
\hline & & & & & \\
\hline Cumulative coal mine dust ( $\mathrm{mg} / \mathrm{m}^{3}$-years) & 1.014 & 0.008 & 0.999 & 1.031 & 0.074 \\
\hline Height (cm) & 0.994 & 0.020 & 0.956 & 1.033 & 0.753 \\
\hline Weight (kg) & 1.020 & 0.008 & 1.004 & 1.036 & 0.015 \\
\hline Non-german nationality & 1.695 & 0.335 & 0.880 & 3.268 & 0.115 \\
\hline Coking coal $^{* *}$ & 1.190 & 0.274 & 0.696 & 2.034 & 0.525 \\
\hline Active smoker* & 1.782 & 0.324 & 0.944 & 3.363 & 0.075 \\
\hline Former smoker $^{\star *}$ & 1.016 & 0.398 & 0.466 & 2.215 & 0.968 \\
\hline \multicolumn{6}{|l|}{ Approach 2} \\
\hline Mean concentration of coal mine dust $\left(\mathrm{mg} / \mathrm{m}^{3}\right)$ & 0.997 & 0.198 & 0.676 & 1.471 & 0.988 \\
\hline Exposure duration (year) & 1.082 & 0.033 & 1.014 & 1.154 & 0.017 \\
\hline Height (cm) & 0.993 & 0.020 & 0.955 & 1.033 & 0.732 \\
\hline Weight (kg) & 1.019 & 0.008 & 1.003 & 1.036 & 0.023 \\
\hline Non-german nationality $^{*}$ & 1.733 & 0.338 & 0.894 & 3.358 & 0.103 \\
\hline Coking coal $^{* *}$ & 1.324 & 0.279 & 0.766 & 2.287 & 0.314 \\
\hline Active smoker* & 1.696 & 0.323 & 0.900 & 3.196 & 0.102 \\
\hline Former smoker $^{* *}$ & 0.935 & 0.399 & 0.428 & 2.043 & 0.866 \\
\hline
\end{tabular}

Statistics: Hazard ratio with standard error; Wald test: z-value, Two-sided p-value; Cl: Confidence interval.

*Reference: German nationality; Gas and flaming coal; Non-smoker.

Table 4: Cox regression models: Hazard ratios for CWP $\geq 0 / 1$ and cumulative exposure to respirable quartz, or mean concentration and exposure duration, and covariables. No. of subjects $=1369$, No. of cases $=72$.

\begin{tabular}{|c|c|c|c|c|c|}
\hline \multirow{2}{*}{\begin{tabular}{|l|} 
Covariable \\
Approach 1 \\
\end{tabular}} & \multirow[t]{2}{*}{ Haz. ratio } & \multirow[t]{2}{*}{ Std. err } & \multicolumn{2}{|c|}{ 95\% Conf. interval } & \multirow[t]{2}{*}{$P>|z|$} \\
\hline & & & & & \\
\hline Cumulative quartz exposure $\left(0.1 \mathrm{mg} / \mathrm{m}^{3}\right.$-years $)$ & 1.083 & 0.022 & 1.038 & 1.130 & $<0.001$ \\
\hline Height (in cm) & 0.991 & 0.020 & 0.953 & 1.031 & 0.659 \\
\hline Weight (in kg) & 1.021 & 0.008 & 1.004 & 1.038 & 0.012 \\
\hline Non-german nationality ${ }^{*}$ & 1.588 & 0.335 & 0.823 & 3.065 & 0.168 \\
\hline Coking coal $^{* *}$ & 2.043 & 0.272 & 1.199 & 3.480 & 0.009 \\
\hline Active smoker* & 1.681 & 0.324 & 0.890 & 3.175 & 0.109 \\
\hline Former smoker $^{* *}$ & 0.899 & 0.401 & 0.410 & 1.973 & 0.791 \\
\hline \multicolumn{6}{|l|}{ Approach 2} \\
\hline Mean concentration of quartz $\left(0.1 \mathrm{mg} / \mathrm{m}^{3}\right)$ & 1.861 & 0.392 & 0.862 & 4.016 & 0.114 \\
\hline Exposure duration (in year) & 1.134 & 0.038 & 1.053 & 1.221 & 0.001 \\
\hline Height (in cm) & 0.990 & 0.020 & 0.952 & 1.030 & 0.619 \\
\hline Weight (in kg) & 1.021 & 0.008 & 1.004 & 1.038 & 0.014 \\
\hline Non-german nationality ${ }^{* *}$ & 1.542 & 0.337 & 0.796 & 2.987 & 0.199 \\
\hline Coking coal $^{* *}$ & 2.131 & 0.281 & 1.229 & 3.697 & 0.007 \\
\hline Active smoker ${ }^{* *}$ & 1.579 & 0.323 & 0.838 & 2.977 & 0.158 \\
\hline Former smoker ${ }^{* *}$ & 0.834 & 0.400 & 0.380 & 1.828 & 0.650 \\
\hline
\end{tabular}

Statistics: Hazard ratio with standard error; Wald test: z-value, Two-sided p-value. ${ }^{*}$ Reference: German nationality; Gas and flaming coal; Non-smoker.

6 months-28 years) and 11.3 quartz-years (range: $0-23$ years). The long-term average concentration of exposure to respirable coal mine dust and quartz was respectively $2.48(\mathrm{sd}=0.65)$ and $0.09(\mathrm{sd}=0.03) \mathrm{mg} / \mathrm{m}^{3}$ at the end of exposure. The cumulative exposure to respirable coal mine dust and quartz was respectively $37.1(\mathrm{sd}=19.8)$ and $1.04(\mathrm{sd}=0.67) \mathrm{mg} / \mathrm{m}^{3}$-years on average.

\section{Cox regression analyses}

Totally, 72 coal workers met the criteria of CWP $\geq$ $0 / 1$, among them 71 of CWP $=0 / 1$ and 1 of $C W P=1 / 0$, during the 30,782 person-years at risk. With respect to time to first $\mathrm{CWP} \geq 0 / 1$, the risk estimates of exposure are presented in Table 3 and Table 4.

Table 3 reports on a Cox regression model on CWP $\geq$ $0 / 1$ that takes the cumulative exposures to respirable coal mine dust using approach 1 . Slightly increased risk (HR $=1.01 ; 95 \%$ CI: $1.00-1.03)$ per $\mathrm{mg} / \mathrm{m}^{3}$-year was found, with marginal statistical non-significance $(\mathrm{p}=0.074)$. After taking the logarithm of cumulative exposure, the effect remains increased with statistical significance as well $(p=0.026)$. The model confirms a significantly in- 
Citation: Yong M, Anderle L, Lenaerts H, et al. (2018) The Risk of Developing Coal Workers' Pneumoconiosis in a German Inception Cohort of Coal Miners of Ruhr Area - Results after 30 Years of Follow-up. Ann Lung Cancer 2(1):39-47

creased risk for coking coal, and a non-significant effect of smoking status was found.

In approach 2, a Cox model analyzing CWP $\geq 0 / 1$ takes simultaneously a long-term average concentration of respirable coal mine dust and exposure duration into account.

Estimated effects for long-term average concentration are not significant $(\mathrm{p}=0.99$ and $\mathrm{p}=0.88$ ) neither on a linear nor on a logarithmic scale, while effect estimate for exposure duration is significant both on linear $(\mathrm{HR}=$ 1.08 per dust-year; 95\% CI: 1.01-1.15, $\mathrm{p}=0.02)$ and on logarithmic scale $(\mathrm{HR}=3.78$ per dust-year; $95 \% \mathrm{CI}$ : 1.42 10.05, $\mathrm{p}=0.01$ ).

Table 4 reports on a Cox regression model on CWP $\geq 0 / 1$ that takes the cumulative exposures to respirable quartz using approach 1. Slightly increased risk (HR = 1.08 per $0.1 \mathrm{mg} / \mathrm{m}^{3}$-year; $95 \% \mathrm{CI}$ : $1.04-1.13$ ) was found, with a statistical significance $(\mathrm{p}<0.001)$. After taking the logarithm of cumulative exposure, the effect remains significant $(\mathrm{p}<0.001)$. The model confirms an increased risk for coking coal $(\mathrm{p}=0.009)$, and a non-significant effect for smokers was found.

Using approach 2, a Cox model considers simultaneously a long-term average concentration of respirable quartz dust and quartz years. The risk estimates of quartz concentration were statistically non-significantly increased, both on linear and on logarithmic scale, while a $13 \%$ ( $p<0.0001)$ increased risk per quartz year was indicated.

\section{Discussion}

Working underground in coalmines has been concerned of developing coal worker's pneumoconiosis $[24,25]$. Extensive endeavor has been made for dust control and health protection in mining industry worldwide and in Germany as well. It is worthwhile evaluating the effectiveness of the measures implemented since decades. We updated the former analysis with follow-up through 1998 [26] with respect to the risk of developing coal workers' pneumoconiosis in an inception cohort in two German coalmines in Ruhr area, with an extended follow-up through 2004.

In the present study, one case $(0.1 \%)$ of $\mathrm{CWP}=1 / 0$ and 71 cases $(5.2 \%)$ of CWP $=0 / 1$ resulted from 30,782 person-years at risk, which yielded a cumulative incidence of 2.34 per 1000 for CWP $\geq 0 / 1$. A previous analysis [26] reported a cumulative incidence rate of 2.9 per 1000 for CWP $=0 / 1$ given 20 years at risk from the same cohort. The authors concluded the low risk estimate cautiously because of probably insufficient latency time. Our finding confirms the low risk estimate from an extended follow-up up to 30 years, with an average of 22 years.
Anyhow, the risk of developing very early signs of CWP $=0 / 1$ was related to cumulative quartz dust exposure. A study of Chinese pottery workers reached the highest silicosis incidence 35 years after first exposure [27]. Thus, the follow-up of our study should be extended to investigate whether risks are masked by latency. The risk estimate is comparatively lower than that from the British Pneumoconiosis Field Research Program (PFR) data of developing CWP $\geq 1$ of $0.60 \%$ (low rank coal) and $0.91 \%$ (high rank coal) based on an average coal mine concentration of $1.5 \mathrm{mg} / \mathrm{m}^{3}$ over 15 years work underground [28]. In contrast, the risk estimates from the US studies $[29,30]$ in US coal mines were 29.1 cases $(2.42 \%)$ and 14.0 cases $(1.02 \%)$ of $\mathrm{CWP} \geq 1$. The higher risk estimates in the US coalmines may be traced to cause of higher coal ranks of the US coals [30], in addition to other determinants, such as size of mines and age of miners [31]. Other reasons for the divergence between the risk estimates of US and German studies lie possibly on the different exposure assessment procedure and different study design or different film reading criteria [32]. A relevant overestimation of original classification based on the data from the employer's liability insurance association has been demonstrated in a study of German porcelain industry cohort [33], which investigated silicosis morbidity by re-reading radiographs retrospectively.

Reading of chest radiographs is the outstanding part of the present study. As described in the methods section, tremendous efforts were given to complete the independent reading of 16,205 radiographs. This is probably the single study with such a high quality standard. Up to 2004, all radiographs were evaluated according to uniform criteria in a standard procedure. After 2008, the radiographs have been achieved digitally and the original films were then no longer available. A validation for reading radiographs in a digital form comparing to the former reading methods of analog X-rays on a lightbox would be necessary. From the perspective of current radiologic standard, one might be concerned of less sensitiveness of chest X-rays to diagnose pneumoconiosis, hence a potential risk of underestimation of incidence rate. At the time of the study, the German legislation required X-ray as a diagnostic standard in occupational health care for routine preventive purpose, with additional weighing of minimizing X-ray dose. At present, updated guideline of International Classification of Occupational and Environmental Respiratory Diseases (ICOERD) for classification using computed tomography scan is available [34] for future research. Due to the mine closing in Walsum in 2008 and subsequently in Heinrich Robert in 2010, the study has not been carried on yet. Hence, we concentrated on the results with follow-up till 2004 in the present analysis. 
Citation: Yong M, Anderle L, Lenaerts H, et al. (2018) The Risk of Developing Coal Workers' Pneumoconiosis in a German Inception Cohort of Coal Miners of Ruhr Area - Results after 30 Years of Follow-up. Ann Lung Cancer 2(1):39-47

Since no manifest pneumoconiosis case CWP $\geq 1 / 1$ (International Labour Organization 1980) was found, we studied the effect of dust exposure with respect to categories $\geq 0 / 1$. Cox regression analyses suggested that $\mathrm{cu}-$ mulative exposure of coal mine dust is associated with an increasing risk with a marginal non-significance. Interestingly, in an alternative approach considering longterm average concentration and exposure duration simultaneously, the exposure duration rather than the exposure concentration came out to be the significant factor, with a greater magnitude of risk estimate. From this result, one would speculate that the average concentration seems to be sufficiently controlled, but the exposure duration is the significant factor in light of prevention for developing CWP. This pattern seems to be consistent with quartz dust. In approach 1, cumulative exposure to respirable quartz indicated apparently an increased risk $(\mathrm{HR}=1.08$; 95\% CI: 1.04-1.13). In approach 2, long-term average concentration of respirable quartz did not reach a significance level, while the risk estimate of exposure duration is highly significant. This result suggests that regulation of working time might be an alternative measure for risk control in addition to workplace limit value.

The unique dose-based concept directed to the cumulative exposure, which combines the regulation of limit value and the duration of working time of dust control program implemented in Germany makes the comparison to studies from other countries rather difficult. Since late of 50's, the coal miners were assigned and deployed based on a dose (cumulative exposure to respirable coal mine dust or quartz dust) concept within an assessment period of two years. Cumulative exposure is in this respect a reasonable exposure metric because of the underlying mechanism of lung overload [35,36], and long latency period of CWP. However, a paradigm change to short-term average concentration in defining work place limit value prevailed in Germany. Concept of long-term average concentration or cumulative exposure was replaced with 8-h time weighted average (TWA) concentration [37]. Effectively, the mean annual respirable coal mine dust concentrations (stationary) decreased from $2.5 \mathrm{mg} / \mathrm{m}^{3}$ in 1975 to $1.9 \mathrm{mg} / \mathrm{m}^{3}$ in 1991 , and further decreased to $1.5 \mathrm{mg} / \mathrm{m}^{3}$ since 2000 in our study. After a significant reduction of limit values of dust concentration, regulation might consider changes connected to working time [38] to control exposure more effectively.

Another potential source of the unexceptional risk observed in our cohort is supposed to result from a healthy worker survivor effect, i.e. a selection that the employees with poor health status exit earlier [39]. The reasons for an exit from the cohort were not documented reliably. Because the duration of follow-up approximates the duration of employment, we believe that the end of employment, either scheduled retirement or downsizing of workforce, are the major reasons for an exit. Furthermore, we compared tentatively the subgroups of those miners with total exposure duration less than 15 years and the latest exit in $1990(\mathrm{~N}=260)$ with the remaining cohort $(\mathrm{N}=1109)$ who would have dropped out in 1990 hypothetically. Only one case of CWP $=0 / 1$ among 260 persons was observed in the early exiting group, while six cases resulted from the remaining cohort, provided the same exposure duration of 15 years. Thus, it is unlikely that the censoring status is associated with health status.

The strengths of this study are worthwhile highlighting. First, the inception cohort being free of relevant exposure prior to study begin, provides a unique data base to study the relationship between dust exposure and health outcomes. To our knowledge, this is the single study with regular measurements of dust exposure and repeated medical examinations in 2 years interval for over 30 years in an inception cohort of coal miners.

The assessment of exposure was comprehensive in comparison with former studies: Ascertaining the exposure to respirable coal mine dust and quartz based on both stationary measurements and individual measurements. No assumption for a retrospective exposure assessment was necessary in the present study. Continuous health surveillance provided complete medical data, for both primary and secondary prevention.

Apart from the unique study design and long-term follow-up of 30 years, the quality of the exposure data is an exemplary success in contrast to the common epidemiological studies that suffer from the uncertain historical exposure estimations. The exposure assessment of the present study stands out in two aspects. Firstly, the performance records document the numbers of shifts exposed, hence the exact exposure duration of each miner can be calculated without any proxy measures. Secondly, the shift-average concentration is available so that the long-term average and cumulative exposure can be derived without any assumptions and extrapolation.

Controlling for potential confounding factors, such as smoking, coal type, and nationality, represents a further strength of the study. The information on smoking status and furthermore pack-years was collected and therefore could be adjusted for. Smoking status was at first selected into the model, and did not show a significant impact on outcome, contrary to the results from another cohort of coal miners in Saar area [10]. Pack-years of smoking was then included into the models, in addition to smoking status. No significant effect of pack-years was present, and the goodness of the model was not improved neither. Therefore, pack-years of smoking were excluded as a covariate because of the strong correlation with smoking status. 
Citation: Yong M, Anderle L, Lenaerts H, et al. (2018) The Risk of Developing Coal Workers' Pneumoconiosis in a German Inception Cohort of Coal Miners of Ruhr Area - Results after 30 Years of Follow-up. Ann Lung Cancer 2(1):39-47

The observed exposure concentration at the workplace in the present study which does not imply an increased risk of pneumoconiosis is not in line with the derivation of a limit value from the translational toxicological models by MAK Commission [8]. This raises the question around whether the translational toxicology models to translate dusts overload findings from rats to humans are reliable for recommendation for threshold limit value or for carcinogen classification of granular bio-persistent particles [9]. Morfeld and co-workers [9] examined the input data for these translational models and pointed out the flaws in terms of alveolar lung surface area, average clearance half time, mean deposition fraction, which are critical for goodness of models. For response and reply, please refer to $[40,41]$. The debates enlighten the limitations of translational toxicology in setting occupational exposure limits from experimental findings. Furthermore, the epidemiological studies of workers, who have exposure to relevant levels of dust, cannot be substituted by animal models because of the different cellular responses to inhaled particles as demonstrated by bronchoalveolar lavage studies in both species.

\section{Conclusion}

CWP is a non-reversible disease, which is, however, preventable under effective dust control. Irrespective of lower coal rank in the studied mines, the continuous dust monitoring and health protection program implemented since the late 1950 years continuously seemed to contribute effectively to the disease control.

\section{Acknowledgements}

We wish to thank the team for their commitment in dust control and health protection in RAG for the past 30 years. The list comprising a number of occupational physicians, industry hygienists, statisticians who have contributed to the work is too long for listing.

The authors are responsible for the method of presentation and opinions expressed in the paper.

\section{Contribution of the Authors}

Study design and study conduction: PM, RD, HL, DB.

Statistical analysis and results interpretation: MY, LA, PM.

Drafting and reviewing of the manuscript: MY, LA, RD, HL, DB, PM.

\section{Conflict of Interest}

This project was sponsored by a research contract between the Institute of Occupational Epidemiology and Risk Assessment (IERA), Evonik Industries AG and the RAG AG. PM, RD, HL, DB are former or current em- ployees of RAG. The design, conduct, analysis, and conclusions of the study are exclusively those of the authors.

\section{References}

1. Laney AS, Attfield MD (2009) Quartz exposure can cause pneumoconiosis in coal workers. Journal of Occupational and Environmental Medicine 51: 867.

2. Attfield MD, Castranova V, Wagner GR (2007) Respiratory disease in coal miners. In: Rom WN, Markowitz S, Environmental and Occupational Medicine. ( $4^{\text {th }}$ edn), Lippincott Williams \& Wilkins, Philadelphia, 345-364.

3. Morfeld P, Piekarski C (1998) Epidemiologie der Pneumokoniose und der chronischen Bronchitis im Steinkohlenbergbau: Ableitung von Grenzwerten für Steinkohlengrubenstaub. Wirtschaftsverlag NW, Bremerhaven, Germany.

4. Miller BG, MacCalman L (2010) Cause-specific mortality in British coal workers and exposure to respirable dust and quartz. Occup Environ Med 67: 270-276.

5. Graber JM, Stayner LT, Cohen RA, et al. (2014) Respiratory disease mortality among US coal miners; results after 37 years of follow-up. Occup Environ Med 71: 30-39.

6. Morfeld P, Lampert K, Emmerich M, et al. (2002) Staubexposition, Pneumokoniose und Lungenkrebs: Eine epidemiologische Studie aus dem Saarländischen Steinkohlenbergbau. Zbl Arbeitsmed Arbeitsschutz Ergon 52: 382-397.

7. Ges Berg V (1991) Gesundheitsschutz-Bergverordnung vom 31. Juli 1991(BGBI. I S. 1751), die zuletzt durch Artikel 5 Absatz 6 der Verordung vom 26. November 2010 (BGBI. I. S. 1643) geändert worden ist. Bundesminister für Wirtschaft, Berlin.

8. Hartwig A (2014) General threshold limit value for dust ( $R$ fraction) (Biopersistent granular dusts) [MAK Value Documentation, 2012]. Wiley-VCH Verlag GmbH \& Co. KGaA.

9. Morfeld P, Bruch J, Levy L, et al. (2015) Translational toxicology in setting occupational exposure limits for dusts and hazard classification- a critical evaluation of a recent approach to translate dust overload findings from rats to humans. Part Fibre Toxicol 12: 3.

10. Morfeld P, Ambrosy J, Bengtsson U, et al. (2001) Aufbau einer epidemiologischen Studie zur Auswirkung von untertägigen Belastungen im Steinkohlenbergbau auf die Lungenfunktion und das Vorliegen einer Pneumokoniose im Röntgenbild bei Steinkohlenbergleuten. Atemw-Lungenkrkh 27: 407-409.

11. Büchte SF (2007) Epidemiologie als Werkzeug zur Erfolgskontrolle für die Begrenzung der Staubbelastung im Steinkohlenbergbau an der Ruhr für den Zeitraum 1974-1998. Fakultät für Energie- und Wirtschaftswissenschaften der Technischen Universität Clausthal.

12. Schulte J (1986) Besonderheiten der Arbeitsmedizin im deutschen Steinkohlenbergbau. Arbeitsmed Sozialmed Präventivmed 21: 245-249.

13. BVOSt (1970) Bergverordnung des Landesobergbergamts Nordrhein-Westfalen für die Steinkohlenbergwerke. Landesoberbergamt Nordrhein-Westfalen, Dortmund, Germany.

14. BVOSt (1986) Bergverordnung des Landesobergbergamts Nordrhein-Westfalen für die Steinkohlenbergwerke vom 20. Landesoberbergamt Nordrhein-Westfalen, Dortmund, Germany. 
Citation: Yong M, Anderle L, Lenaerts H, et al. (2018) The Risk of Developing Coal Workers' Pneumoconiosis in a German Inception Cohort of Coal Miners of Ruhr Area - Results after 30 Years of Follow-up. Ann Lung Cancer 2(1):39-47

15. (1980) Guidelines for the Use of ILO International Classification of Radiographs of Pneumoconiosis. International Labour Organization.

16. Ulmer WT (1985) Begutachtung in der pneumologie: Silikose. Prax Klin Pneumol 39: 674-676.

17. Wazau G (1973) Bedienungsanleitung zum Staubmeßund Probenahmegerät MPG II System SFI/IGF. Mess- und Prüftechnik, Berlin.

18. CEN EN 481 (1993) Workplace atmospheres: Size fraction definitions for measurement of airborne particles in the workplace. Comité Européen de Normalisation, Brussels.

19. Bauer HD (1995) Staubjahre. Möglichkeiten ihrer Ermittlung unter Einbeziehung unerschiedlicher Messsysteme und Verfahren der Arbeitseinsatzlenkung-Bearbeitungshinweise. Hauptverband der gewerblichen Berufsgenossenschaften (HVBG), Sankt Augustin, Germany.

20. Breslow NE, Day NE (1987) Statistical methods in cancer research. Volume II-The design and analysis of cohort studies. (82 ${ }^{\text {nd }}$ edn), International Agency for Research on Cancer, Lyon.

21. Cox D (1972) Regression models and life tables. Journal of the Royal Statistical Society 34: 187-220.

22. Cox D (1975) Partial likelihood. Biometrika 62: 269-276.

23. Stata Corp (2014) Statistical Software: Release 13. Statistical Software. College Station, StataCorp LP, TX.

24. Jacobsen M (1971) A science which ought to be honourable. Trans Soc Occup Med 21: 38-42.

25. Campbell H, Lyons JP, Gough J, et al. (1973) Coalworkers' pneumoconiosis. BMJ 3: 351.

26. Morfeld P, Ambrosy J, Bengtsson U, et al. (2002) The risk of developing coal worker's pneumoconiosis in German coal mining under modern mining conditions. The Annals of Occupational Hygiene 46: 251-253.

27. Sun Y, Bochmann F, Morfeld P, et al. (2011) Change of exposure response over time and long-term risk of silicosis among a cohort of Chinese pottery workers. Int J Environ Res Public Health 8: 2923-2936.

28. Hurley JF, Maclaren WM, Medicine loO (1987) Dust-related risks of radiological changes in coalminers over a 40-year working life: Report on work commissioned by NIOSH. Institute of Occupational Medicine, Edinburgh, Scotland.

29. Attfield MD, Morring K (1992) An investigation into the relationship between coal workers' pneumoconiosis and dust exposure in U.S. coal miners. Am Ind Hyg Assoc J 53: 486492.
30. Attfield MD, Seixas NS (1995) Prevalence of pneumoconiosis and its relationship to dust exposure in a cohort of U.S. bituminous coal miners and ex-miners. Am J Ind Med 27: 137-151.

31. Laney AS, Petsonk EL, Hale JM, et al. (2012) Potential Determinants of Coal Workers' Pneumoconiosis, Advanced Pneumoconiosis, and Progressive Massive Fibrosis Among Underground Coal Miners in the United States, 2005-2009. Am J Public Health 102: S279-S283.

32. Hurley F, Kenny L, Miller B (2002) Health impact estimates of dust-related disease in UK coal miners: methodological and practical issues. The Annals of Occupational Hygiene 46: $261-264$

33. Mundt KA, Birk T, Parsons W, et al. (2011) Respirable crystalline silica exposure-response evaluation of silicosis morbidity and lung cancer mortality in the german porcelain industry cohort. J Occup Environ Med 53: 282-289.

34. Hering KG, Hofmann-Preiß K, Kraus T (2014) Update: standardized CT/HRCT classification of occupational and environmental thoracic diseases in Germany. Radiologe 54: 363-384.

35. Morrow PE (1988) Possible mechanisms to explain dust overloading of the lungs. Fundam Appl Toxicol 10: 369-384.

36. Oberdörster G (1995) Lung particle overload: Implications for occupational exposures to particles. Regul Toxicol Pharmacol 21: 123-135.

37. Greim H (1996) Ableitung von schichtbezogenen MAK-Werten für Stäube aus Langzeitgrenzwerten. In Toxikologisch-arbeitsmedizinische Begründungen von MAK-Werten. WILEY-VCH Verlag $\mathrm{GmbH} \& \mathrm{Co}$. KGaA, Weinheim, 1-22.

38. Kenny LC, Hurley F, Warren ND (2002) Estimation of the risk of contracting pneumoconiosis in the UK coal mining industry. Ann Occup Hyg 46: 257-260.

39. Checkoway H, Pearce N, Kriebel D (2004) Research methods in occupational epidemiology. International Journal of Epidemiology 33: 1115-1156.

40. Hartwig A (2015) Reply on behalf of the 'Permanent Senate Commission for the Investigation of Health Hazards of Chemical Compounds in the Work Area' (MAK Commission). Part Fibre Toxicol.

41. Morfeld P, Bruch J, Levy L, et al. (2016) Response to the Reply on behalf of the 'Permanent Senate Commission for the Investigation of Health Hazards of Chemical Compounds in the Work Area' (MAK Commission) by Andrea Hartwig Karlsruhe Institute of Technology (KIT). Part Fibre Toxicol 13: 1. 